\title{
USE OF CYBER-PHYSICAL SYSTEMS FOR THE KEY ROLES OF QUANTITY SURVEYORS
}

\author{
WEERASOORIYA. A.D. ${ }^{1}$, PERERA. B.A.K.S. ${ }^{2}$, GALLAGE. S.D. ${ }^{3}$ \& DISARATNA. P.A.P.V.D.S. ${ }^{4}$ \\ 1,2,3,4Department of Building Economics, University of Moratuwa, Katubedda, Sri Lanka

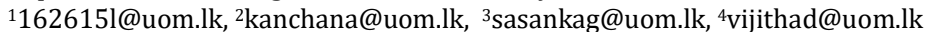

\begin{abstract}
Cyber-physical systems (CPS) enable the synergistic integration of virtual models with the physical environment. CPS are being increasingly recognized because of their ability to improve information management in construction projects, make project delivery efficient, and enhance facilities management. The use of virtual models in the construction industry is growing. A quantity surveyor (QS) is responsible for estimating and monitoring construction costs from project inception to completion. The use of CPS could integrate the physical environment with the digital information available to QSs. Hence CPS has the potential to streamline the workflow related to key roles of QSs. Thus, the aim of the study was to evaluate the ability of CPS to facilitate the key roles expected of a QS. The study used a qualitative approach, consisting of 18 semi-structured interviews. The interview findings were analysed using manual content analysis. The literature review revealed the need for CPS in the construction industry and identified the key roles of QSs. The interviewees identified the existing CPS and their supportive applications, technologies and proposed new systems. The study findings provide insights on the reforms required in the key roles of QSs when using CPS.
\end{abstract}

Keywords: Adaptability, Cyber Physical Systems, Key Roles, Quantity Surveyor

\section{Introduction}

Digitalisation has influenced all sectors of the industry (Ratna et al., 2018). Information Technology (IT) is a key technology used in the modern world, which provides both opportunities and challenges when improving the quality of life of people and their communities (Osei-Bryson et al., 2014). Abawajy (2012) stated that organisations are increasingly relying on IT to maintain competitive advantages and improve their services. The use of IT in the construction industry has become indispensable in areas such as building design, project planning and scheduling, cost control and budgeting, and computer-aided facility management (Ikediashi et al., 2016).

Smart construction will be a trend in the future because innovative technologies, such as Building Information Modelling (BIM), cloud computing, the Internet of Things (IoT), mobile internet, big data and automation (Zhai et al., 2009). Such advancements of technology followed by the concept of Industry 4.0 will be used increasingly in construction (Chelyshkov, 2019). With these innovations of data capturing, communication and computation, digital resources can be seamlessly integrated with the physical engineered components (Maskuriy et al., 2019). Cyber Physical Systems (CPS) are dynamic systems that can effectively integrate cyber and physical components using the modern sensor, computing and network technologies (Ghazani \& Lotf, 2012).

According to RICS (2019), Artificial Intelligence (AI) and the IoT have now become a core components of construction industry operations. The rapid developments in Information and Communication Technology (ICT) have encouraged the construction industry to explore the CPS approach (Akanmu et al., 2014). CPS can be used in construction for progress monitoring, construction 
process controlling, as-built documentation, and sustainable building practices (Akanmu et al., 2014). Thus, the implementation of CPS will have an impact on the professionals working in the construction industry.

Being a professional, a Quantity Surveyor (QS) working in the construction industry will have to handle project financing (Perera et al., 2007). The use of computers by QSs has grown steadily since the introduction of stand-alone computers in the early 1980s for project estimation (Brook, 2008). According to Chandramohan et al. (2020), the employment model of QSs has been completely redefined because of the innovations and advanced IT applications introduced to the construction industry. Therefore, traditional work practices are no longer effective for QSs working in construction (Dada et al., 2012).

According to Towey (2012), advancements in the field of ICT had QSs involved in document communication systems, project management planning, cost management systems, video and teleconferencing, webcams, conference displays, forums, E-tendering, cloud computing, and BIM. The transformation of the work practices of QSs has positively influenced the construction industry as it has increased the productivity, performance, and the quality and integration of construction processes (Hassan et al., 2019). With the introduction of CPS, professionals would be able to create a virtual copy of their physical environments and make informed decisions using sensor data and digitalized plant models (Hermann et al., 2016). Wao (2015) stated that the future growth of the quantity surveying profession would depend on the advancements made in areas such as IT, and sustainable design and construction. Therefore, the investigation of the impact of innovative technologies, such as CPS introduced recently, on the role of a QS is imperative. CPS being a recent approach to visualisation of construction process that evolves with other technologies of industry 4.0 (Maskuriy et al., 2019), there has been several studies on the adaption of CPS to construction industry. In addition to that, few independent studies have been conducted on adapting CPS related technologies quantity surveying practices. However, collective use of CPS on the key roles performed by QSs has not been focused by the existing literature. Therefore, this study reviews the existing literature to investigate the current level of usage of CPS and CPS-related technologies in the construction industry while exploring the roles of present-day QSs. Subsequent semi structured interviews help identify the CPS and CPS-related technologies that help perform key roles QSs and how CPS could transform these roles of QSs.

\section{Literature Review}

A literature review was first conducted to explore the existing knowledge on components of CPS and usage of CPS in the construction industry. There literature sources mainly consisted of journal articles and conference proceedings in order to gather latest knowledge on the subject area. In addition to CPS, literature review also focused on identifying key roles of QSs while exploring the current and potential use of CPS to perform identified roles QSs. Thereby, literature review help establish the potential use of CPS to the way QS perform their roles.

\subsection{OVERVIEW OF CYBER-PHYSICAL SYSTEMS (CPS)}

CPS are dynamic systems that can effectively integrate cyber and physical components using modern sensors, and computing and network technologies (Ghazani et al., 2012). Resources such as machines, materials, and labour are the physical components of CPS, while data analysis, applications, services, and decisions are the cyber components of CPS. Computation and communication are used by CPS to introduce new capabilities to physical structures that interact with physical processes intensively (Tao et al., 2019). According to Anumba et al. (2010), CPS integrate several physical and virtual components through automation and robotics.

The devices used in the automation sector have recently become heterogeneous and CPS are expected to address this heterogeneity in the future (Riedl et al., 2013). Leitão et al. (2016) stated that CPS in industrial infrastructures have to deal with mechatronics, communication, and information technology when managing the distributed physical processes and systems of the infrastructure. As Riedl et al. (2013) discussed, the automation systems open to future demands reflect the opportunities available for CPS. The last two decades have seen substantial progress in AI and robotics (Jämsä-Jounela, 2007). Momin et al. (2015) highlighted that CPS will contribute to the value, safety, efficiency, productivity, and performance of future automation systems used in construction. Therefore, in future, CPS will play a major role in the construction sector. 


\subsection{CPS IN CONSTRUCTION INDUSTRY}

Correa (2018) noted that CPS is a far-reaching technology that can solve the recurring problems of the construction industry. Chelyshkov (2019) agreeing with Correa (2018) found that the applications of CPS in the architecture, engineering and construction industry relied on the technologies that are already available and those that are being developed. Use of supportive applications of CPS and technologies in construction activities, such as monitoring of building efficiencies (Bonchi et al., 2019), integration of building information models and physical constructions (Akanmu et al., 2014), planning and operation of mobile cranes in construction sites (Chelyshkov, 2019) and construction industry overall (Correa, 2018; Akanmu et al., 2014) have been identified by past researchers. According to Kim et al. (2013) and Dewit (2015), CPS could be useful for the tracking of the progress of different construction activities of large complex projects. CPS can capture physical data, and thus can improve prefabrication operations while ensuring that they serve their purpose (Vähä et al., 2013). Kim et al. (2013) highlighted that the use of CPS would improve the safety and defect management in manufacturing. They further highlighted that CPS technologies can help material tracking. Kim et al. (2013) believed that, the ability of CPS to respond to physical inputs during process automation would enable the use of robots to perform design, construction, and demolition activities. Thus, the technology used in CPS is a far-reaching technology that would address the recurrent problems of the construction industry (Correa, 2018).

\subsection{ROLES OF QS}

A QS, also known as a construction economist or cost manager, is a member of the team of construction industry professionals involved in the estimation and monitoring of construction costs, starting from project feasibility studies to project completion (AIQS, 2020). In the early days, QSs worked only for project consultants, contractors, or clients (Shafiei et al., 2008). Today, they are involved in the insurance, financial, manufacturing, taxation, and valuation industries as well (Chandramohan et al., 2020). Table 1below lists the roles of QSs identified from the literature.

\begin{tabular}{|c|c|c|c|c|c|c|c|c|c|}
\hline \multirow[b]{2}{*}{ Role of QSs } & \multicolumn{9}{|c|}{ Authors } \\
\hline & A & B & C & D & $\mathbf{E}$ & $\mathbf{F}$ & G & $\mathbf{H}$ & I \\
\hline Preliminary estimation & ? & ? & & ? & ? & & ? & ? & \\
\hline Contract administration & ? & & & & & ?] & & ] & \\
\hline Bills of Quantities (BOQs) preparation & & & & & & & & & ? \\
\hline Priced BOQ examination & & & & & & & & & ? \\
\hline Cost planning & 国 & ? & ? & & & & ?] & ? & ? \\
\hline Cost estimation & & & & & & & & & ? \\
\hline Procurement advice & & ? & ? & & & ?] & & ? & ? \\
\hline Measurement and quantification & & ? & & ] & ? & ?] & ] & ? & \\
\hline Specification preparation & ? & & & & & & & ? & \\
\hline Contract documentation & & ? & & & ?] & & ? & ? & \\
\hline Contractual advice & & & & & & & & & ? \\
\hline Cost control & & & ? & ? & & & & 国 & \\
\hline Interim valuations and payments & & ? & & ? ? & & & & ] & ? \\
\hline Financial reporting & & & & & & & ? & ] & ? \\
\hline Final account preparation & & ? & & ? & & & & & ? \\
\hline Tender examination & & & & & & & & & ? \\
\hline Contractual claim settlement & & 国 & ? & & & & & 国 & \\
\hline Project management & & & & & & & & ] & ? \\
\hline Value management & & & & & & & & 国 & ? \\
\hline Facilities management & & & & & & & & ? & ? \\
\hline Dispute resolution & & & & & & & & ? & ? ? \\
\hline Life cycle cost analysis & & & & & & & & ? & \\
\hline Programming & & & & & & & & ] & \\
\hline Insurance valuation & & & & & & & & ? & \\
\hline Building surveying & & & & & & & & 司 & \\
\hline Sustainability advice & & & & & & & & 国 & \\
\hline Post occupancy evaluation & & & & & & & & 司 & \\
\hline Investment appraisal & & & & & & & & ? & \\
\hline Building information service provision & & & & & & & & ] & \\
\hline Research methodologies and technologies & & & & & & & & ] & \\
\hline
\end{tabular}

Table1, Roles of QSs identified from the literature 
Even though QSs have to play many diversified roles, most of the previous researchers have identified preliminary estimation, measurement and quantification, contract administration, cost planning, procurement advice, contract documentation, cost control, and interim valuations and payments as the roles of QSs. Wao (2015) stated that because of the opportunities that would become available for advancement in areas such as IT, and sustainable design and construction, the future growth of the profession would depend on the steps taken to address economic recessions. Oladapo (2006) noted that the use of IT software makes the jobs of QSs easy, improves their decision-making abilities, and helps them reduce the overall project costs without sacrificing project functionality and quality.

\subsection{USE OF CPS BY QUANTITY SURVEYORS}

The use of IT software has been proposed to overcome the shortcomings of manual quantification of construction works (Oladapo, 2007). According to Ashworth et al. (2013), through project financial management and cost consultancy services to the clients and designers throughout the project construction process a QS should ensure that construction resources are used for the benefit of the society. Real-time project information allows informed decisions to be made by project participants, such as project managers, site engineers and construction workers (Kim et al., 2013). Because BIM has already promoted the digitalisation of the construction industry, it is important to consider the relevance of Industry 4.0 technologies to construction (Correa, 2018). Furthermore, according to Correa (2018), CPS in construction would reduce or eliminate manual information gathering and reduce the time taken to produce progress reports or enable their preparation in real-time. Thus, CPS will enable QSs to focus on aggregated-values and decision-making tasks. According to Wao (2015), the roles of QSs vary from country to country and in the United Kingdom and in some African and Asian countries, they can play core roles in construction, such as arbitration and overall project management. As Kim and Park (2018) stated, BIM, cost estimation and planning technologies, and risk management and value engineering are being increasingly required in quantity surveying. By implementing BIM for cost estimation, input information can be improved and the knowledge and understanding of the estimator can be enhanced to obtain accurate cost estimates (Ismail et al., 2016).

\subsection{PROPOSED USE OF CPS BY QUANTITY SURVEYORS}

Although BIM is being widely used in the design and engineering phases of building projects, only few attempts have been made to combine sensor technology and BIM and make the combination the real-time or on-line data repository of the building (Vähä et al., 2013). BIM applications include the automation of operations, management of knowledge, classification of documents, improvement of labour productivity and visualization of construction management data (Chiu et al., 2013). The entire life of a building can be divided into several stages: design, production, construction and operation stages and the end of life (Lützkendorf \& Lorenz, 2006). Linares et al. (2019) categorised supportive applications and technologies of a construction project under main four stages: planning, design, construction, and operation and maintenance stages. CPS can be used in the construction stage to improve progress monitoring, control the construction processes, prepare as-built documentation, and implement sustainable building practices (Akanmu et al., 2014) using the data collected from sensors and translating that data into information for use in a model. In building and facilities management, BIM uses sensor readings to monitor resource positions (Dewit, 2015). New sensor technologies and the broad use of BIM will offer new methods for addressing the requirements and operations of a building throughout its life cycle (Vähä et al., 2013). By accommodating a $4^{\text {th }}$ dimension (4D),' time', and a $5^{\text {th }}$ dimension (5D),' cost,' which explicitly relate to the quantification, modification, and extraction of data embedded within a BIM model, BIM can become the primary source of information required in quantity surveying (Stanley \& Thurnell, 2014). Building architecture is closely related to the environmental conditions of the building location (Keating et al., 2017). Using 3D printing techniques, the cost structure of buildings can be altered based on the overall costs of the raw materials used (Keating et al., 2017).

\subsection{USE OF CPS TO TRANSFORM THE KEY ROLES OF QUANTITY SURVEYORS}

Kim and Park (2018) observed that integration of cost dimension with 5D BIM allows such information to be shared among stakeholders improving efficiency of many duties performed by QSs during the precontract stage. Similarly, authors further emphasised the potential to configure the same model to be "live linked" to actual progress with use of other simulation tolls which could facilitate many post contract activities performed by QSs. Similarly, with the recent developments in ICT, CPS are being used in multiple instances in construction industry (Lazarova-Molnar et al., 2016). Few studies (Akanmu et al., 2014; 
Anumba et al., 2010; Chelyshkov, 2019; Correa, 2018; Lazarova-Molnar et al., 2016) have been conducted on the use of CPS in the construction industry. Availability of multiple CPS applications and the complexity of their development process have narrowed down most research studies to individual CPS applications, focused on addressing the challenges offered by CPS (Lazarova-Molnar et al., 2016). Further, studies conducted on CPS in relation to QSs are often concentrated on individual CPS applications. According to AIQS (2020), QSs often have to make decisions involving large sums of money based on the information generated by them. During this process QSs are required to perform different roles which involve analysis of information generated from multiple resources. A quantity-surveying firm interested in accuracy has to use ICT (Agyekum et al., 2015).

\section{Method Of Study}

This study explored the use of CPS to facilitate the core roles expected of QSs. As Saunders et al. (2009) and Hammarberg et al., (2016) explained, the qualitative research approach allows a researcher to assess opinions, behaviours, and relationships associated with the subject of the research study. The approach would enable the exploration of the key roles performed by QSs and supporting technologies of CPS used by QSs based on experience of experts. Moreover, a qualitative approach improves self-understanding and the understanding of the human conditions, particularly those related to human experience and behaviours (Mafuwane, 2011). Therefore, using a qualitative approach, the use of CPS to facilitate the key roles of QSs can be ascertained.

Kajornboon (2005) explained that, data collection method of a research study has to be selected based on the research goals and versatility of available methods. The literature revealed that, the traditional role of QS had diversified over the recent years. Hence, the study initially focused on identifying the key roles performed by QSs. CPS being a relatively new concept to the construction industry which combines information retrieved from several exiting and developing CPS applications, research subsequently focused on identifying existing and potential use of CPS applications facilitate and transform key roles of QSs. Responses to above aspects would depend on the respondent's knowledge and exposure to different applications of CPS. Therefore, semi- structured interviews were selected for data collection as it provides a basic framework, which allows the researcher to discuss and revisit the responses received with flexibility MacDonald and Headlam (2011).

CPS being a concept which evolves with the advancement in ICT, prospective respondents had to be from a quantity surveying background who are conversant with new technologies in the construction industry. With purposive sampling, a heterogeneous sample of 18 interviewees belonging to different age groups having experience in both industry and academia, were identified for the semi structured interviews. The respondents' views, opinions, and perspectives on the subject of the study were obtained while allowing situational questions based on the professional opinions expressed. Interviews were primarily focused on identifying key roles of QSs among the 30 diversified roles identified from the literature. Subsequently, applicably and use of identified CPS and supportive CPS applications perform key roles of QSs were explored. Each interview, which lasted for 60-75 min, was conducted either as an online or face-to-face interview. A brief description of each interviewee is provided in Table 2.

\begin{tabular}{|l|l|l|l|l|l|}
\hline No & \multicolumn{1}{|c|}{ Designation } & $\begin{array}{c}\text { Type of } \\
\text { Organization }\end{array}$ & \multicolumn{1}{|c|}{ Country } & $\begin{array}{c}\text { Experience } \\
\text { Years) }\end{array}$ & Area of Expertise \\
\hline I.01 & PhD researcher & Educational & England & 3 & Digital Twins/ New technologies \\
\hline I.02 & Contractor QS & Contractor & $\begin{array}{l}\text { United Arab } \\
\text { Emirates } \\
\text { (UAE) }\end{array}$ & 4 & New software/ New technologies \\
\hline I.03 & Senior lecturer & Educational & New Zealand & 23 & New technologies \\
\hline I.04 & Contractor QS & Contractor & UAE & 6 & New technologies \\
\hline I.05 & Contractor QS & Contractor & UAE & 5 & New technologies \\
\hline I.06 & Cost manager & Employer & UAE & 4 & New technologies \\
\hline I.07 & PhD researcher & Educational & Australia & 4 & Blockchains/ Carbon Emission \\
\hline I.08 & PhD researcher & Consultancy & Australia & 5 & BIM \\
\hline I.09 & Consultant QS & Consultancy & Sri Lanka & 5 & New technologies \\
\hline I.10 & Director & Consultancy & Sri Lanka & 13 & New technologies/ Tendering \\
\hline I.11 & Director & Contractor & Sri Lanka & 26 & Contract specialist/ New technologies \\
\hline I.12 & $\begin{array}{l}\text { Contract } \\
\text { specialist }\end{array}$ & Consultancy & Sri Lanka & 9 & BIM/ New technologies \\
\hline I.13 & Senior Lecturer & Educational & Sri Lanka & 20 & \\
\hline
\end{tabular}




\begin{tabular}{|l|l|l|l|l|l|}
\hline I.14 & $\begin{array}{l}\text { Procurement } \\
\text { Engineer }\end{array}$ & Contractor & Sri Lanka & 6 & Procurement/BIM \\
\hline I.15 & PhD Researcher & Educational & Sri Lanka & 3 & New technologies \\
\hline I.16 & PhD Researcher & Educational & Hong Kong & 6 & New technologies \\
\hline I.17 & Project manager & Consultancy & USA & 18 & New software/ New technologies \\
\hline I.18 & PhD Researcher & Educational & England & 6 & New technologies \\
\hline
\end{tabular}

Table 2, Details of the interviewees

Given the semi structured interviews adapted for the collection of data from a heterogeneous sample, the responses consisted information based on different practices and exposure to CPS. Hence, the method adapted for the analysis of data had to be flexible and accommodate the diverse information in order to produce meaningful findings. The manual content analysis enhances the user's focus on the data set and reduces the diversion of the user's attention from the contextual meaning of the data to the process (Cope, 2014). Thus, content analysis using manual coding was adopted for the data analysis. Based on different opinions of the respondents', identified roles were classified with manual coding. The assigned code was later used to identify the applicability of the CPS.

\section{Findings}

The primary data of the study were collected from semi-structured interviews. Manual content analysis of the findings revealed the use of CPS applications key roles of the QSs.

\subsection{IDENTIFICATION OF THE KEY ROLES OF QUANTITY SURVEYORS}

The literature review identified 30 roles of QSs (Table 2). The interviewees were asked to identify the key roles of a QS from among those listed in Table 2. The interviewees I.10, I.11, I.13, and I.17 who had the most experience in the industry maintained that several new roles have been assigned to QSs in recent years with the introduction of new technologies and concepts. However, respondents further clarified that apart from few instances, many new roles have been associated with traditional roles of QS. The majority of the interviewees highlighted that the responsibilities attached to most of the roles were similar. Therefore, interviewees ignored the diversified roles and identified as key roles only 9 of the 30 roles identified from the literature. The identified key roles are preliminary estimation, measurement and quantification, contract administration, cost planning, procurement advice, contract documentation, tender evaluation, cost control and interim valuations and payments. The interviewee I.04 argued that roles such as project management should be included in the list. However, the other interviewees were of the view that diversified roles could not be considered key roles. Further, I.11 argued that many roles based on contractual decision making could be classified under contract administration. Similarly, preliminary estimation could include new roles such as life cycle cost analysis, and investment appraisal. The identified key roles are listed in Table 3.

\begin{tabular}{|c|l|c|l|}
\hline Code & Role & Code & Role \\
\hline R1 & Preliminary estimation & R6 & Tender and contract documentation \\
\hline R2 & Measurement and quantification & R7 & Cost planning \\
\hline R3 & Contract administration & R8 & Cost control \\
\hline R4 & Preparation of B0Qs & R9 & Procurement advice \\
\hline R5 & Interim valuations and payments & & \\
\hline
\end{tabular}

Table 3, Key roles expected of a QS

\subsection{CURRENT USE OF CPS AND ITS SUPPORTIVE APPLICATIONS BY QUANTITY SURVEYORS}

A list of 22 CPS applications and technologies were identified from the literature. However, from the 22 applications, the interviewees removed Internet, Email, 5G, Portable Devices, and Video and Audio Communication from the list because they were considered common applications. In addition to that, Internet of Things (IoT) also was removed because it was considered a collective term used for all internetbased services. Further, 3D printing, GIS, Photogrammetry, Exoskeletons, Robotics and Autonomous Vehicles also were removed as they were not directly related to the key roles of QSs. Hence, out of the 22 applications interviewees removed 12 applications. The interviewees suggested five additional applications used with CPS which are, Estimating (ES) Software, Taking Off (TO) software, Project Planning 
(PP) Software, Contract Administration (CA) Software and 3D Model TO. Subsequently, 15 CPS and CPS related applications that facilitate key roles of QSs were identified. Similarly, interviewees highlighted those certain applications have already been implemented in the industry while other applications were still under development and testing phase. Therefore, 15 applications were classified into two categories namely, existing applications and proposed applications. The left side of Figure 1 illustrates how existing CPS and CPS-related applications are used to support the key roles of a QS.

Figure 1 below depicts the use of existing and proposed CPS on the key roles of a QS. The left side portion of figure 1 use of existing technologies while right side explains the use of proposed applications. Based on the responses most of the existing CPS applications facilitate the estimation, quantification, preparation of BOQs and interim valuation roles performed by QSs. I.03 and I.11 identified above roles as core functions expected from a QS which are critical for cost management of construction projects. While agreeing with that statement, majority of respondents also highlighted above roles as most time-consuming and error-prone activities performed by the QSs. Compared to number of CPS applications that supported estimation and quantifications, relatively limited number of applications supported cost planning and cost controlling. I.13 and I.17 highlighted that ability of an application to automatically update changes significantly contributes to the cost planning aspects. Procurement advice and tender documentation were other key roles which had been well facilitated by existing CPS. I.10, I.13 and I.14 stated that traditional procurement procedures that relied on hard copies had been digitalized with the recent development in ICT. I.12 and I.14 highlighted that many organizations had adapted E-Tendering methods. Contract administration aspect of QSs had also been satisfactorily addressed by CPS Applications. The majority of the interviewees observed that BIM implementation has laid the foundation for digital contract management. According to them, the existing software supports the handling of contractual data in a Common Data Environment (CDE). I.02, I.05 and I.12 stated that several construction companies who have already implemented contract administration using CPS are now hesitant to expand it because of security threats.

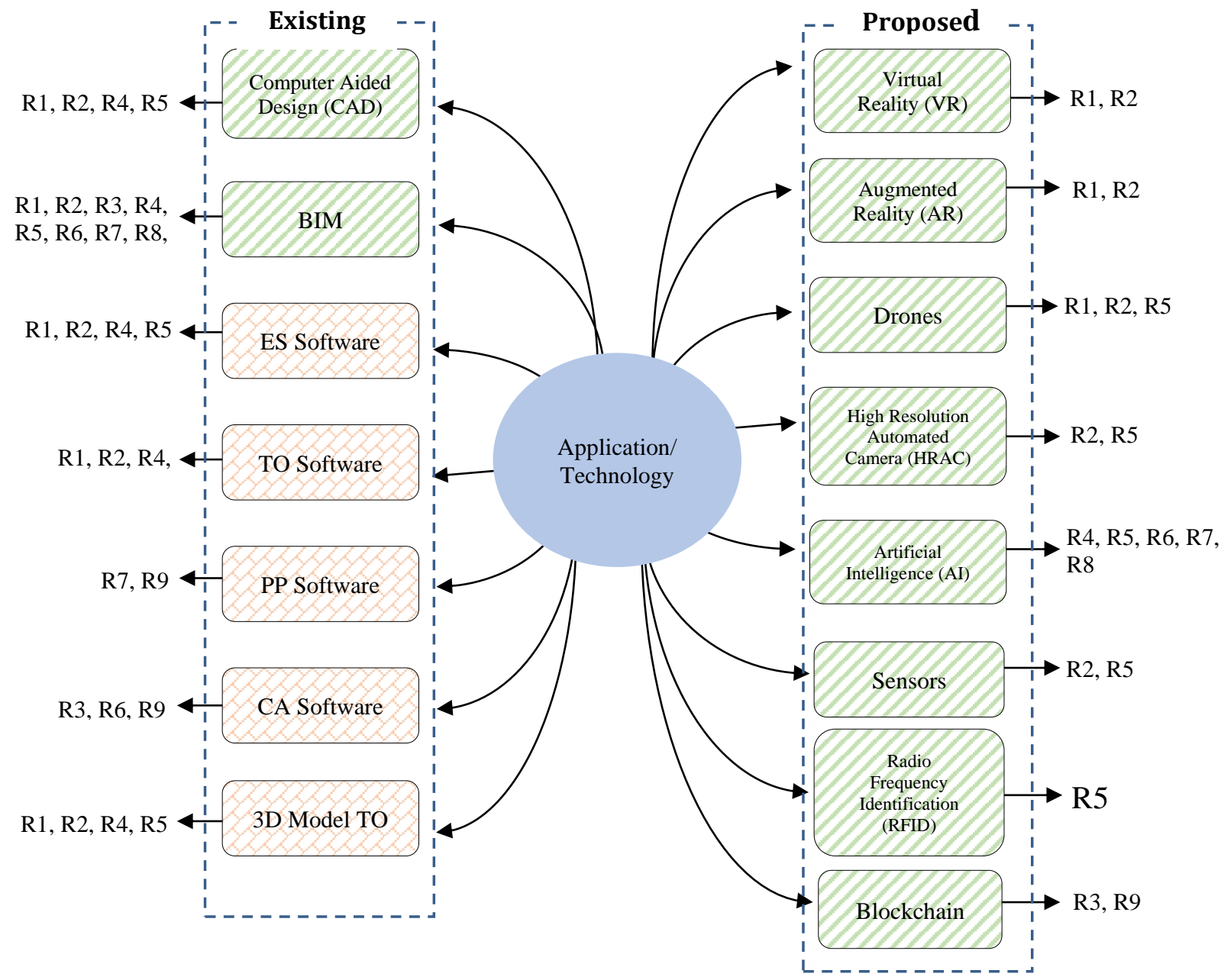




\begin{tabular}{|c|c|}
\hline & Identified from the literature \\
\hline & $\begin{array}{l}\text { Suggested by interviewees } \\
\text { Estimating (ES) Software, Taking Off (TO) software, Project Planning (PP) Software, Contract Administration } \\
\text { (CA) Software and 3D Model TO }\end{array}$ \\
\hline $\begin{array}{l}\text { Removed afte } \\
\text { Common a } \\
\text { Not directl }\end{array}$ & $\begin{array}{l}\text { nterviews } \\
\text { lication - Internet, Email, 5G, Portable Devices, and Video and Audio Communication } \\
\text { elated to QS's role - 3D printing, GIS, Photogrammetry, Exoskeletons, Robotics and Autonomous Vehicles }\end{array}$ \\
\hline
\end{tabular}

Figure1, Supportive applications and technologies of CPS related to the key roles of a QS

BIM based software were highlighted as a versatile application that supported all key role of QSs. I.08 and I.13 pointed out that compared to another existing CPS applications BIM was well established concept in the construction industry. Hence wide variety of applications have been developed to facilitate almost all functions performed in construction projects. Modelling based applications such as CAD, ES, TO and 3D Model TO were found to support roles such as estimation, quantification, preparation of BOQs and interim valuation. All interviewees agreed that these existing applications efficient and accurate delivery of activities related to above roles. Both Contract Planning and Project Planning applications facilitate procurement advising while focusing on contract administration and cost planning respectively.

\subsection{PROPOSED USE OF CPS AND THEIR SUPPORTIVE APPLICATIONS BY QUANTITY SURVEYORS}

As already mentioned, the right side of Figure 1 illustrates how the proposed CPS technologies would facilitate the key roles of a QS.

Interim valuations and payments activities of QSs were found to be supported by a majority of proposed CPS applications. I.01, I.13, I.15, I.16, I.17, and I.18 believed that the implementation of these systems would automate site monitoring, enabling QSs to update the project progress and cost plans to suit the situation. Similarly, measurement and quantification was another key role focused by majority of proposed CPS applications. I.04, I.08 and I.17 highlighted that compared to existing CPS which support quantification with regard to the design, almost all of the proposed CPS focused measuring real time construction progress by capturing site progress. I.07 and I.14 highlighted the potential of using drones to collect information on site progress without visiting the site. According to I.05, sensors and RFID can be integrated with material delivery and production processes to track their progress. The role of estimation which was already supported by existing CPS was found to be supported by several proposed CPS as well. The interviewee I.01 mentioned that Augmented Reality (AR) and Virtual Reality (VR) could be used to create models containing sufficient details to help QSs prepare estimates. According to I.01, these models assist visualisation of projects while improving the accuracy of estimates.

Use of AI could support most key roles performed by QSs. I.01, I.07 and I.09 believed that AI together with machine learning could assist QSs make better decisions with regard to cost planning, cost control, interim valuations. Majority of the interviewees agreed that, with CPS, quantification and BOQ preparation would be automated. However, I.11 and I.13 who had more experience argued that human input would still be required to take decisions on intricate matters. I.07 suggested that blockchain, being incorruptible, would prevent security risks associated with contract administration. Thus, the use of this technology would produce definitive contracts, stored electronically in one single location with the history of its versions clearly recorded and accessible only to the relevant parties. Respondents further explained that, such features would assist QSs to ensure the confidentiality of contractual data, especially during pre and post contract stages.

\section{Discussion}

The discussion of the findings of a study with those knowledgeable on the subject of the study is important even though the existing knowledge has not yet not been developed up to the expected level. The section below compares existing knowledge with study findings.

\subsection{USE OF EXISTING CPS TO TRANSFORM THE KEY ROLES OF QUANTITY SURVEYORS}

This study primarily focused on the use of CPS to facilitate key roles of QSs whereas, previous studies conducted by Akanmu et al. (2013), Correa (2018) focused on the integration of CPS with the construction industry. Findings of the study revealed that, apart from 3D printing, GIS, Photogrammetry, Exoskeletons, 
Robotics and Autonomous Vehicles which are highly related to other engineering disciplines, majority of existing CPS could facilitate key roles of QSs. In addition to that, ES, TO and 3D Model TO software had specifically focused on key roles of QSs such as estimation, quantification, preparation of BOQs and interim valuation. Interviewees believed that these existing CPS have focused on reducing the time spent on repetitive tasks. This acknowledges the observations of Linares et al. (2019) on automation of simple and repetitive activities as a significant advantage of CPS. Similarly, the ability of existing CPS to reduce errors associated with performing the above roles was highlighted through the study reaffirming findings of Oladapo (2007) that overcoming human blunders associated with manual processes, been a major concern during the development of CPS.

Conferring to Correa (2018), respondents also highlighted that, existing CPS substantially contribute to the digitalization of procurement arrangement, tender documentation and contract administration by enabling efficient information gathering while optimizing the compilation of contractual documents in a collaborative environment. However, findings revealed that only a few existing CPS applications could facilitate cost planning and cost control aspects of QS. Respondents acknowledged the existence of CPS applications that allow cost planning and cost controlling as mentioned by Akanmu et al. (2014). However, Inability of most existing CPS applications to update cost information in real time was identified as a barrier to facilitate cost planning and controlling. Nonetheless, BIM based applications were identified as versatile CPS applications which could facilitate all key roles of QSs agreeing with Correa, (2018) on the contribution of BIM concept to digitalize most aspects of construction industry.

\subsection{USE OF PROPOSED CPS TO TRANSFORM THE KEY ROLES OF QUANTITY SURVEYORS}

According to the study findings, the proposed technologies of CPS would streamline the key role of QSs by enabling real time data capturing as mentioned by Kim et al. (2013). Endorsing the literature review findings, the interviewees highlighted that QSs should use real time project information to make informed decisions. Sensors, drones, and AI would significantly contribute to real time data capturing required for the quantification and interim valuation. The findings of the study tally with the findings of Vähä et al (2013), which revealed that new sensor technology and the broad use of BIM. Such applications would help capture real time data required for cost controlling and interim reports. The study findings agree with Lazarova-Molnar et al. (2016) on the advantages of having AR and VR for the immersive visualisation of a project. The technologies would enable QSs to provide accurate estimations and have access to additional data. The findings further highlighted the opportunities available to combine real time data with AR and VR $s$ to help the QSs with the preparation of interim valuations and controlling costs. Hence, the findings coincide with Akanmu et al. (2013) on potential uses of CPS applications for progress monitoring, construction process controlling, as-built documentation, and sustainable building practices.

In addition to that, findings also highlighted the potential use of AI for assisting decision making related to tendering and cost controlling. Contracts are the backbone of construction projects. The interviewees while agreeing with Correa (2018) on the ability of BIM to handle contract management emphasized the ability of blockchain technology to ensure the validity and security of contractual data. This feature would assist QSs to ensure the confidentiality of contractual data, especially during pre and post contract stages. The findings of the study also confirm the findings of Anumba et al. (2010), which revealed that CPS could establish new procurement approaches in the construction industry. The interviewees highlighted that by using Blockchains and BIM, lean procurement approaches could be made by eliminating the multitude of intermediaries currently involved in construction projects using conventional approaches, the new approaches will enable cost savings that will allow a client to exercise strict control of the project and make project cost, time, and scope clear.

\section{Conclusions and Recommendations}

CPS are defined in the literature as dynamic systems that can integrate cyber and physical components using modern computing and network technologies. Data captured from the physical components using sensors and other modern technologies will be transferred to a digital environment. Within which the data can be modelled, analysed and processed to produce information that will be used in return to improve physical components. As other industrial sectors adopted CPS, , the construction industry too would have to adopt new technological inventions gradually. Therefore, this study aims to explore how these different CPS applications would facilitate roles performed by QSs. 
Proceeding a thorough literature review, a semi-structured interviews with 18 professionals conducted to identify key roles performed by QSs and use of CPS application perform identified roles. The interview findings narrowed down the number of key roles that the QSs are expected to play to nine: preliminary estimation, tender and contract documentation, measurement and quantification, cost planning, contract administration, cost control, preparation of BOQs, procurement advice and interim valuations and payments. Subsequently, the applicability of CPS and their supporting technologies to help the QSs in their key roles were explored. The finding revealed 7 exiting CPS applications and 8 proposed CPS applications that would contribute QSs to perform their key roles. Majority of existing CPS applications support estimation, quantification, preparation of BOQs and interim valuation, related tasks by minimising human blunders and time consumed. Further, BIM based software stood out among the existing CPS applications that could support all identified key roles of QSs. When considering the proposed CPS applications, they focus on efficiently capturing data from physical components whereas existing CPS focused on processing provide data. Additionally, technologies such as AR, VR and AI could significantly contribute to the visualisation of captured data. AI together with other technologies such as machine learning could assist QSs in decision-making process as well. The use of blockchain and BIM could help implement new procurement approaches.

This study primarily identified the key roles of QSs and how existing and proposed CPS applications could contribute to the quantity surveying practices related to the identified roles. As identified from the study use of both existing and proposed CPS could elevate the functionality of QSs as key professionals in the construction industry. By knowing the capabilities of existing applications, QSs could select the suitable CPS application based on the tasks they wish to perform. Further studies can be conducted on identifying strategies to bridge existing CPS applications with other roles that were not supported initially. Similarly, identification of the barriers that hinder the implementation of proposed CPS and developing strategies mitigate such barriers would enable CPS to serve QSs perform more efficiently.

\section{References}

Abawajy, J:2012, User preference of cyber security awareness delivery methods. Behaviour \& Information Technology, Taylor \& Francis, Oxfordshire, 33(3), 237-248.

Agyekum, K., Ayarkwa, J., and Acheampong, A:2015, Incorporating information technology in quantity surveying practice in Ghana: challenges and benefits. International Journal of Engineering, Materials and Energy Research Centre, Tehran, 13, 49-56.

AIQS:2020, "What is QS?" Available from: www.aiqs.com (accessed 06 June 2021).

Akanmu, A., Anumba, C., and Messener, J:2014, Active monitoring and control of light fixtures during building construction and operation. Cyber-Physical Systems Approach. Journal of Architectural Engineering, ASCE, Reston, 20(2)

Anumba, C., Akanmu, A., and Messner, J:2010, Towards a cyber-physical systems approach to construction. 2010 Construction Research Congress, Banff, 528-538

Ashworth, A., Hogg, K., and Higgs, C:2013, Willis's Practice and Procedure for the Quantity Surveyor, Wiley, Hoboken

Awoyemi, T., Aje, O., and Olanipekun, A: 2014, Quantity surveyor's experience and construction project performance in Rwelamila, P.D. \& Ogunlana (ed), Construction in developing countries research roadmap, International Council for Research and Innovation in Building and Construction, CIB, Lagos, 295-307

Bonchi, A., Carbonari, A., Cucchiarelli, A., Messi, L., Pirani, M., and Vaccarini, M:2019, A cyber-physical system approach for building efficiency monitoring, Automation in Construction, Elsevier, Amsterdam, 102, 68-85.

Brook, M:2008, Estimating and Tendering for Construction Work, Butterworth-Heinemann., Amsterdam

Chandramohan, A., Perera, B., and Dewagoda, K:2020, Diversification of professional quantity surveyors' roles in the construction industry: the skills and competencies required. International Journal of Construction Management, Taylor \& Francis, Oxfordshire, 1-8

Chelyshkov, P:2019, Computer-aided design of cyber-physical building systems. E3S Web of Conferences, EDP Sciences, Les Ulis, 97

Chiu, C.-Y., and Russell, A: 2013, Design of a construction management data visualization environment: A bottom-up approach. Automation in Construction, Elsevier, Amsterdam, 35, 353-373

Cope, D.G: 2014, Computer-assisted qualitative data analysis software, Oncology nursing forum, Oncology Nursing Society, Pittsburgh, 41(3), 322-323

Correa , F:2018, Cyber-physical systems for construction industry. IEEE Industrial Cyber-Physical Systems, IEEE, New Jersey

Cunningham, T:2014, The Work and Skills Base of the Quantity Surveyor in Ireland - An Introduction. Technological University Dublin, Dublin 
Dada, J., \& Jagboro, G: 2012, Core skills requirement and competencies expected of quantity surveyors: perspectives from quantity surveyors, allied professionals and clients in Nigeria. Construction Economics and Building, UTS ePRESS, Sydney, 78-90.

Dewit, A: 2015, Komatsu, Smart Construction, Creative Destruction, and Japan's robot revolution. The Asia-Pacific Journal, Japan Focus, 13(5), 2.

Ghazani, S., \& Lotf, J: 2012, A Study on QoS Models for Mobile Ad-hoc Networks. International Journal of Modeling and Optimization, IACSIT Press, Singapore, 634-636.

Hammarberg, K., Kirkman, M., \& de Lacey, S: 2016, Qualitative research methods: when to use them and how to judge them. Human Reproduction, IRL Press, Oxford, 31(3), 498-501.

Hassan, M., \& Nadeem, A: 2019, Towards digitizing the construction industry; state of the art of construction 4.0. Proceedings of International Structural Engineering and Construction, ISEC Press, Astana 6, pp. 1-6..

Hermann, M., Tobias, P., \& Boris, O: 2016, Design principles for Industry 4.0 scenarios. Annual Hawaii International Conference on System Sciences, Kohala Coast, 3928-3937

Ikediashi, D. I., \& Ogwuelek, A. C: 2016, Assessing the use of ICT systems and their impact on construction project performance in the Nigerian construction industry. Journal of Engineering, Design and Technology, Taylor \& Francis, Oxfordshire, 14(2), 252-276.

Ismail, N., Drogemuller, R., Beazley, S., and Owen, R: 2016, A Review of BIM Capabilities for Quantity Surveying Practice, MATEC Web of Conferences, EDP Sciences, Les Ulis, 66, p. 00042

Jämsä-Jounela, P.-L: 2007, Future trends in process automation. IFAC Proceedings Volumes, Elsevier, Amsterdam, $40(1), 1-10$.

Kajornboon, Annabel Bhamani. "Using interviews as research instruments." E-journal for Research Teachers, Chulalongkorn University, Bangkok, 2(1), 1-9

Kasim, N., Latiffi, A., \& Syazli Fathi, M: 2013, RFID Technology for Materials Management in Construction Projects A Review. International Journal of Construction Engineering and Management, ASCE, Reston, 2(4A), 7-12.

Keating, S., Leland, J., Cai, L., and Oxman, N: 2017, Toward site-specific and self-sufficient robotic fabrication on architectural scales, Science Robotics, American Association for the Advancement of Science, Washington, 2(5)

Kim, C., Park, T., Lim, H., \& Kim, H: 2013, On-site construction management using mobile computing technology. Automation in Construction, Elsevier, Amsterdam,35, 415-423

Kim, K., and Park, K: 2018, Housing information modelling for BIM-embedded housing refurbishment, Journal of Facilities Management, Emarald, Bingley, 16(3), 299-314.

Lazarova-Molnar, S., Shaker, H., \& Mohamed, N: 2016, Reliability of cyber physical systems with focus on building management systems. 2016 IEEE 35th International Performance Computing and Communications Conference

Leitão, P., Colombo, A., \& Karnouskos, S: 2016, Industrial automation based on cyber-physical systems technologies:

Prototype implementations and challenges, Computers in Industry, Elsevier, Amsterdam, 81, 11-25.

Linares, D., Anumba, C., \& Esfahan, N: 2019, Overview of supporting technologies for cyber-physical systems implementation in the AEC industry. Computing in Civil Engineering, ASCE, Reston, 495-504

Lützkendorf, T., and Lorenz, D: 2006, Using an integrated performance approach in building assessment tools, Building Research \& Information, Taylor \& Francis, Oxfordshire, 34(4), 334-356

Macdonald, S., and Nicola H: 2011, "Research Methods Handbook". Available from: http://www. cles. org. uk/wpcontent/uploads/2011/01 (accessed 02 May 2021)

Mafuwane, B.M: 2011, The contribution of instructional leadership to learner performance, University of Pretoria, Pretoria

Maskuriy , R., Selamat, A., Maresova , P., Krejcar, O., and Oladipo, D: 2019, Industry 4.0 for the construction industry: review of management perspective, Economies, MDPI, Basel 7(3), 68

Momin, S., Pati, J., and Nale, R: 2015, Enhancement of Road Construction Sector using Automation, International Research Journal of Engineering and Technology, Fast Track Publications, Tamilnadu, 2(3), 978-983.

Oke, A: 2010, Perception of construction professionals to the performance of Nigerian quantity surveyors. Journal of Building Performance, Taylor \& Francis, Oxfordshire, 1(1)

Oladapo, A: 2006, The Impact of ICT on Professional Practice in the Nigerian Construction Industry. The Electronic Journal of Information Systems in Developing Countries, Wiley, New Jersey, 24(1), 1-19.

Olanrewaju, A., \& Anahve, P: 2015, Duties and responsibilities of quantity surveyors in the procurement of building services engineering. Procedia Engineering, Elsevier, Amsterdam, 352-360.

Osei-Bryson, K.-M., \& Vogel, D: 2014, Special issue on cyber-security for development. Information Technology for Development, Taylor \& Francis, Oxfordshire, 20(2), 93-95.

Perera, B., Hemajith, S., Ginge, K., \& Amarathunga, R: 2007, Quantity surveyor as the technical appraiser in the Sri Lankan financial industry. Built Environment Education Conference. Sri Lanka

Ratna, S., Astuti, E., Utami, H., Rahardjo, K., \& Arifin, Z: 2018, Characteristics of tasks and technology as a driver of task-technology fit and the use of the hotel reservation information system. Journal of Information and Knowledge Management Systems, KMS, Singapore, 48(4), 579-595. 
RICS. (2019). "Future of Surveying". Available from: https://www.rics.org/globalassets/ricswebsite/media/news/future-of-the-profession-post-consultation-report.pdf (accessed 02 May 2021)

Riedl, M., Zipper, H., Meier, M., \& Diedrich, C: 2013, Automation meets CPS. IFAC Proceedings Volumes, Elsevier, Amsterdam, 46(7), 216-221.

Saunders, M., Lewis, P., \& Thornhill, A: 2009, Research Methods for Business Students. Pearson, New York.

Shafiei, M., \& Said, I: 2008, The Competency requirements for quantity surveyors: enhancing continuous professional development. Sri Lankan Journal of Human Resource Management, Colombo, 2(1), 17-27.

Stanley, R., \& Thurnell, D: 2014, The benefits of, and barriers to, implementation of 5D BIM for quantity surveying in New Zealand. Construction Economics and Building, UTS ePRESS, Sydney, 14(1), 105-117.

Tao, F., Qi, Q., Wang, L., \& Nee, A: 2019, Digital Twins and Cyber-Physical Systems toward Smart Manufacturing and Industry 4.0: Correlation and Comparison. Engineering, Elsevier, Amsterdam, 5(4), 653-661.

Towey, D: 2012, Construction Quantity Surveying - A Practical Guide for the Contractor's QS. Wiley Blackwell, Hoboken

Vähä, P., Heikkilä, T., Kilpeläinen, P., Järviluoma, M., \& Gambao, E: 2013, Extending automation of building construction - Survey on potential sensor technologies and robotic applications. Automation in Construction, Elsevier, Amsterdam, 36, 168-178

Wao, J: 2015, Predicting the future of quantity surveying profession in the construction industry. Journal of Construction Project Management and Innovation, Nova Science Publishers, New York, 5(2), 1211-1223.

Zhai, D., Goodrum, P., Haas, C., \& Caldas, C: 2009, Relationship between Automation and Integration of Construction Information Systems and Labor Productivity. Journal of Construction Engineering and Management, ASCE, Reston, 135(8), 746-753. 